\title{
Palladium oxidation leads to methane combustion activity: Effects of particle size and alloying with platinum ${ }^{\circ}$ (c)
}

\author{
Cite as: J. Chem. Phys. 151, 154703 (2019); doi: 10.1063/1.5126219 \\ Submitted: 3 September 2019 - Accepted: 25 September 2019 • \\ Published Online: 18 October 2019
}

\author{
Emmett D. Goodman, ${ }^{\top}$ Angela A. Ye, ${ }^{1}$ Aisulu Aitbekova, ${ }^{1}$ Oliver Mueller, ${ }^{2}$ Andrew R. Riscoe, \\ Temy Nguyen Taylor, Adam S. Hoffman, ${ }^{2}$ (D) Alexey Boubnov, ${ }^{2}$ Karen C. Bustillo, ${ }^{3}$ (D) Maarten Nachtegaal, \\ Simon R. Bare, ${ }^{2}$ (D) and Matteo Cargnello ${ }^{1, a)}$ (iD
}

\author{
AFFILIATIONS \\ 'Department of Chemical Engineering and SUNCAT Center for Interface Science and Catalysis, Stanford University, \\ Stanford, California 94305, USA \\ ${ }^{2}$ Stanford Synchrotron Radiation Lightsource, SLAC National Accelerator Laboratory, Menlo Park, California 94025, USA \\ ${ }^{3}$ National Center for Electron Microscopy, Molecular Foundry, Lawrence Berkeley National Laboratory, Berkeley, \\ California 94720, USA \\ ${ }^{4}$ Paul Scherrer Institute, Villigen, Switzerland
}

Note: The paper is part of the JCP Special Topic Collection on Catalytic Properties of Model Supported Nanoparticles. a) Author to whom correspondence should be addressed: mcargnello@stanford.edu

\begin{abstract}
Pd- and Pt-based catalysts are highly studied materials due to their widespread use in emissions control catalysis. However, claims continue to vary regarding the active phase and oxidation state of the metals. Different conclusions have likely been reached due to the heterogeneous nature of such materials containing various metal nanoparticle sizes and compositions, which may each possess unique redox features. In this work, using uniform nanocrystal catalysts, we study the effect of particle size and alloying on redox properties of Pd-based catalysts and show their contribution to methane combustion activity using operando quick extended x-ray absorption fine structure measurements. Results demonstrate that for all studied Pd sizes $(3 \mathrm{~nm}-16 \mathrm{~nm})$, Pd oxidation directly precedes $\mathrm{CH}_{4}$ combustion to $\mathrm{CO}_{2}$, suggesting Pd oxidation as a prerequisite step to methane combustion, and an oxidation pretreatment shows equal or better catalysis than a reduction pretreatment. Results are then extended to uniform alloyed $\mathrm{Pt}_{\mathrm{x}} \mathrm{Pd}_{1-\mathrm{x}}$ nanoparticles, where oxidative pretreatments are shown to enhance low-temperature combustion. In these uniform alloys, we observe a composition-dependent effect with Pt-rich alloys showing the maximum difference between oxidative and reductive pretreatments. In Pt-rich alloys, we initially observe that the presence of Pt maintains Pd in a lower-activity reduced state. However, with time on stream, PdO eventually segregates under oxidizing combustion conditions, leading to a slowly increasing activity. Overall, across particle sizes and alloy compositions, we relate increased catalytic activity to Pd oxidation, thus shedding light on previous contrasting results related to the methane combustion activity of these catalysts.
\end{abstract}

Published under license by AIP Publishing. https://doi.org/10.1063/1.5126219

\section{INTRODUCTION}

With recent discoveries of untapped shale gas reserves and the development of new technologies to extract resources from them, methane and shale gas have received newfound attention as a transition fuel toward green energy technologies. In part, this interest is because, compared to coal and gasoline, $\mathrm{CH}_{4}$ burns more cleanly on an energy-per-carbon basis. ${ }^{1}$ However, if $\mathrm{CH}_{4}$ is directly emitted into the atmosphere, it poses a significant contribution to global warming. On a per mole basis, $\mathrm{CH}_{4}$ presents an impact of 28-84 times that of $\mathrm{CO}_{2}$, suggesting that preventing methane release to or capturing it from the atmosphere could lead to a drastic 
reduction in greenhouse effects. ${ }^{2}$ In order to minimize environmental impacts of using methane as a transition fuel, efficient technologies to combust $\mathrm{CH}_{4}$ into $\mathrm{CO}_{2}$ need to be developed and improved. Compared to homogeneous fuel combustion, combustion catalysts operate at low temperatures to minimize high-temperature formation of $\mathrm{NO}_{\mathrm{x}}$ and $\mathrm{SO}_{\mathrm{x}}$ and should utilize minimal quantities of precious metals. Such technologies will be employed in natural gas-powered vehicles, as well as gas-powered turbines, and may lead the way toward broadly improving hydrocarbon-combustion catalysts. $^{3}$

Pd- and Pt-based combustion materials are well-known as the most effective catalysts for low-temperature emissions control, and grams of these precious metals are present in modern-day emissions control catalysts. ${ }^{5}$ Numerous studies have focused on optimizing the efficiency of these systems, which aim at increasing their activity at lower temperatures while minimizing the amount of the precious metals required. Much work has been done in optimizing catalyst support $^{6-8}$ and promoters, ${ }^{9,10}$ and recent studies have even targeted control of nanoparticle size. ${ }^{6,11-13}$ Additional catalyst optimization emerges in the study of bimetallic Pt-Pd catalysts with different studies reporting various optimal Pt:Pd ratios. ${ }^{14-16}$ Even for a nominal alloy catalyst composition, single particle nanostructure could vary between random alloys, core-shell and phase segregated structures, and intermetallic structures, each with their own catalytic reactivity. The development of structure-property relationships for emissions control materials will help facilitate the rapid design of improved catalysts.

The redox behaviors of emission control catalysts are a fundamental parameter which governs catalyst activity, and much work has been aimed at correlating the oxidation state with catalytic activity. Unfortunately, even for monometallic Pd catalysts, there is still no consensus in the literature regarding the most active Pd oxidation state. Different studies report conflicting results claiming $\mathrm{Pd}, \mathrm{PdO}$, or Pd-PdO interfaces as the active site for the methane combustion reactions. Confusion in the literature may be exacerbated by different reaction conditions. Calculations have supported lower activation energy barriers on $\mathrm{PdO}$ surfaces compared to $\mathrm{Pd}$ $\left(62 \mathrm{~kJ} \mathrm{~mol}^{-1}\right.$ vs $\left.73 \mathrm{~kJ} \mathrm{~mol}^{-1}\right)$ although the mechanism varies depending on the specific surface structure. ${ }^{17}$ In situ Surface X-Ray Diffraction (SXRD) has found that either metallic Pd particles or sufficiently thick $\mathrm{PdO}(101)$ films can contribute to high methane conversion. ${ }^{1}$ Another work has studied the formation of Pd-PdO interfaces and their potential to be the active site for methane combustion. ${ }^{19,20}$ Although it is generally agreed that the addition of Pt to Pd catalysts reduces the propensity of $\mathrm{Pd}$ to oxidize, this aspect has been identified as both a promoting and a deactivating effect in different works studying the effect of Pt on Pd and the effect of different alloy compositions. ${ }^{16,20,21}$ Johns et al. studied the oxidation state of several $\mathrm{Pt} / \mathrm{Pd} / \mathrm{Al}_{2} \mathrm{O}_{3}$ that were aged at $750{ }^{\circ} \mathrm{C}$ for $10 \mathrm{~h}$ and found $\mathrm{Pd}$ to be in both the oxidized and reduced states. Singleparticle analysis showed uniformly alloyed $\mathrm{Pt} / \mathrm{Pd}$ NPs coexisting with a separate $\mathrm{PdO}$ phase, and high activity was attributed to the metallic Pt/Pd surface. No phase segregation or enrichment was observed. ${ }^{22}$ In a recent work, Nie et al. characterized the structure of $\mathrm{Pt} / \mathrm{Pd}$ catalysts after oxidative treatments and observed the presence of PdO@PtPd core-shell structures co-existing with oxidized Pt nanoclusters. The former was determined as the active phase. ${ }^{2}$ Clearly, an understanding of active oxidation states is convoluted when there are numerous oxidation states coexisting within the same material.

Correlating the oxidation state of combustion catalysts with their activity has been a persistent challenge in the field of catalytic combustion. Various assignments may be due to two main factors: (1) a misattribution of the catalyst oxidation state under combustion conditions and (2) characterization of structures which are not the catalytically relevant phase. The first issue exists in studies involving reductive pretreatments, followed by testing under high-temperature oxidizing conditions: although the catalyst starts as metallic $\mathrm{Pd}$, the oxidation state under combustion conditions is not well-known. PdO is the thermodynamically stable phase at $\mathrm{T}<700^{\circ} \mathrm{C}$ in air. However, due to kinetic bottlenecks in oxidation and reduction, it is not obvious what the oxidation state of a $\mathrm{Pd} / \mathrm{Al}_{2} \mathrm{O}_{3}$ catalyst is under reaction conditions. ${ }^{17,19}$ In methane combustion, molecular oxygen and water are oxidizing species, while methane is reducing, and together these chemical potentials determine catalytic activity and Pd oxidation state at a given temperature. Thus, identification of the oxidation state of the active element is challenging without the use of in situ measurements. The second issue is relevant in systems that contain particles of various sizes, which may oxidize and reduce at different temperatures and at different rates. In this case, polydispersity may result in characterization of features which do not correspond to observed catalytic properties. For example, although many small particles may quickly oxidize to highly active $\mathrm{PdO}$ nanoparticles, material characterization may indicate metallic $\mathrm{Pd}$ as the active phase due to a single, slowly oxidizing Pd aggregate.

In heterogeneous and polydisperse materials, measuring bulk properties such as the oxidation state might not result in data from the most active catalytic species. This problem can be addressed by utilizing nanoparticles that are uniform in size and composition. In this work, using colloidal synthesis approaches, we synthesize catalysts with controlled particle size and composition in order to correlate catalytic activity with the oxidation state of Pd. In uniform monometallic catalysts, we observe Pd oxidation as a prerequisite to combustion activity suggesting that the catalyst needs to be at least partially oxidized prior to the methane combustion reaction. The catalyst may be preoxidized before catalysis due to intentional catalyst pretreatment or the catalyst must oxidize under reaction conditions prior to catalytic combustion. No combustion is observed without Pd being present in at least a partially oxidized state. This result is first demonstrated by utilizing operando XAS, where Pd oxidation precedes methane combustion across all particle sizes. Measurements demonstrate that preoxidizing the catalyst leads to lower-temperature methane combustion activity once the pretreated material is exposed to reaction conditions, thus avoiding the need to preoxidize the material in situ. By contrast, while reducing the material results in decreased activity, the catalyst reactivates on-stream under oxidative reaction conditions. With this knowledge, we study the effect of NP composition on oxidation and catalysis and find that increased Pt content leads to lower activity and slow on-stream activation, while decreased Pt content leads to high activity and rapid activation. Elemental mapping combined with X-Ray Photoelectron Spectroscopy (XPS) demonstrate that uniformly alloyed nanoparticles segregate to produce an oxidized PdO phase. Across sizes and compositions, Pd oxidation is demonstrated as a prerequisite to high catalytic activity. 


\section{EXPERIMENTAL}

\section{A. Synthesis of colloidal nanocrystal catalysts}

All syntheses were performed with standard air-free Schlenk line techniques. Size-controlled Pd nanocrystal catalysts were synthesized according to a previous report. Briefly, $\mathrm{Pd}(\mathrm{acac})_{2}(35 \%$ Acros Organics) was used as a metal precursor. 1-octadecene (ODE, 90\%, Acros Organics), 1-tetradecene (TDE, 94\%, Alfa Aesar), and 1-dodecene, (DDE, 93\%-95\%, Acros Organics) were used as reaction solvents; 1-oleylamine (OLAM 70\%, Aldrich), oleic acid (OLAC 90\%, Aldrich), and trioctylphosphine (TOP, 97\%, Aldrich) were used as surfactants and reducing agents. All chemicals were used as received. The general synthetic methodology is as follows. $\operatorname{Pd}(\mathrm{acac})_{2}$ was charged to a three-neck flask with solvents, OLAM, and OLAC at room temperature. The mixture was evacuated for $15 \min (<270 \mathrm{~Pa})$, TOP was added, and the mixture was degassed for another $30 \mathrm{~min}$ at $50^{\circ} \mathrm{C}$. All solutions were a pale translucent light yellow. The reaction was flushed with nitrogen and heated $\left(\sim 40^{\circ} \mathrm{C}\right.$ $\left.\mathrm{min}^{-1}\right)$ to the desired reaction temperature. After $15 \mathrm{~min}$ of reaction at the appropriate reflux temperature under vigorous magnetic stirring, the solution was cooled to room temperature. For specific reagent quantities and additional material characterization, see our previous report. $^{24}$

For alloyed nanoparticle synthesis, a solution of $7.1 \mathrm{~nm}$ colloidal Pd NPs in hexanes $(\sim 5 \mathrm{mg} / \mathrm{ml})$ was used as seeds to grow $\mathrm{Pt}_{\mathrm{x}} \mathrm{Pd}_{1-\mathrm{x}}$ via a seed-mediated growth process. For each alloy synthesized, the same Pd seed solution was used to ensure similar particle sizes across catalysts. To $0.5 \mathrm{ml}(2.5 \mathrm{mg})$ Pd NPs, a specific amount of $\mathrm{Pt}(\mathrm{acac})_{2}$ (98\%, Acros Organics) for a targeted alloy composition was added along with $10 \mathrm{ml}$ OLAM as a solvent and a surfactant. This mixture was carefully degassed at $80^{\circ} \mathrm{C}$ for $30 \mathrm{~min}$ to remove dissolved gases and low boiling point solvents (i.e., residual hexanes). The 3-neck flask was then refilled with $\mathrm{N}_{2}$, quickly ramped to $250^{\circ} \mathrm{C}$, and let react for $30 \mathrm{~min}$. The solution was cooled to room temperature, and the reaction solution was precipitated twice using isopropanol and ethanol. The resulting solution was stored in $\sim 3 \mathrm{ml}$ hexanes to which $20 \mu \mathrm{l}$ OLAM was added to increase NP stability.

Metal concentrations of synthesized colloidal nanoparticle solutions were found by Thermogravametric Analysis (TGA) of the colloidal solution. An appropriate amount of nanoparticles was dispersed in hexanes and added to a dispersion of $\sim 2 \mathrm{~g}$ support stirred in hexanes. Complete adsorption occurred immediately, but solutions were left stirring for $1 \mathrm{~h}$. The solid was recovered by centrifugation and dried at $60^{\circ} \mathrm{C}$ overnight. Before catalytic tests, all samples were sieved below $180 \mu \mathrm{m}$ grain size, fast-treated at $700{ }^{\circ} \mathrm{C}$ for $30 \mathrm{~s}$ in a furnace to remove ligands from synthesis, ${ }^{25}$ then sieved again below $180 \mu \mathrm{m}$ grain size. Monometallic Pd catalysts (Sec. III A) were all 1.0 wt. \% Pd. Alloy catalysts (Sec. III B) were all 0.1 wt. \% Pd and a corresponding amount of Pt (Table S1).

\section{B. Microscopy techniques}

Transmission electron microscopy (TEM) images were acquired on a FEI Tecnai operating at $200 \mathrm{kV}$. High Angle Annular Dark Field Scanning Transmission Electron Microscopy (HAADFSTEM) images were acquired on a FEI TitanX operating at $300 \mathrm{kV}$ at the National Center for Electron Microscopy at the Lawrence
Berkeley National Laboratory. EDS-Maps were performed on the TitanX utilizing a SuperEDS detector consisting of four windowless silicon drift detectors with a total solid angle of 0.7 steradians. Map acquisition time was typically $~ 5-10 \mathrm{~min}$ at a beam current of $330 \mathrm{pA}$, unless otherwise noted. For powder samples, lacey $\mathrm{C} / \mathrm{Cu}$ grids were shaken with the catalyst powder to prepare samples for imaging. Particle size distributions were calculated by measuring $>100$ nanoparticle diameters, using ImageJ software. ${ }^{26}$ EDS spectrum quantification was performed via the Cliff-Lorimer method of the Pt-L edge and the Pd-L edge. ${ }^{2}$

\section{Super X-ray absorption spectroscopy}

Super XAS spectra were acquired in transmission mode at the Pd K-edge (24 $350 \mathrm{eV}$ ) at the Super XAS beamline at the Swiss Light Source (SLS, Paul Scherrer Institute). ${ }^{28,29}$ The SLS operated at an energy of $2.4 \mathrm{GeV}$ and a ring current of $400 \mathrm{~mA}$. The polychromatic beam resulting from a $2.9 \mathrm{~T}$ bending magnet was collimated by a $\mathrm{Pt}$ coated collimated mirror at $2.5 \mathrm{mrad}$, monochromatized by a continuously scanning $\mathrm{Si}$ (111) channel-cut monochromator, which oscillated at $1 \mathrm{~Hz}$, and subsequently focused using a Pt coated toroidal mirror to a spot size of $100 \times 100 \mu \mathrm{m}^{2}$ at the sample position. Transmission scans were performed using $15 \mathrm{~cm}$ long Ar filled ionization chambers before and after the catalytic reactor, and a third ionization chamber was used to record a reference spectrum of a Pd foil simultaneously. For operando measurements, the catalytic activity was monitored by an online Hiden mass-spectrometer, which was connected directly into the end of the capillary to minimize dead volume. $\sim 20 \mathrm{mg}$ catalyst was placed inside a thin quartz capillary held in place on both ends by quartz wool. A thermocouple was placed directly into the catalytic bed to monitor temperature, which was controlled by two heat blowers aimed at the cell.

Before operando combustion experiments, each catalyst was ramped in $10 \mathrm{ml} \mathrm{min}{ }^{-1} 5 \mathrm{vol} . \% \mathrm{O}_{2} / \mathrm{He}$ to $400{ }^{\circ} \mathrm{C}$ at $20^{\circ} \mathrm{C} \mathrm{min}^{-1}$, returned to room temperature, and reduced at room temperature in $20 \mathrm{ml} \mathrm{min}^{-1} 5 \mathrm{vol} . \% \mathrm{H}_{2} / \mathrm{He}$. This treatment was performed twice for each catalyst before operando collection. Next, $10 \mathrm{ml} \mathrm{min} \mathrm{m}^{-1}$ methane combustion gases $\left(0.5 \mathrm{vol} . \% \mathrm{CH}_{4}, 4.0\right.$ vol. $\% \mathrm{O}_{2}$, balance

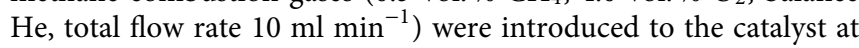
room temperature, and spectra were collected in the reduced catalyst state, while the feed composition stabilized on the mass spectrometer. Then, under operando combustion conditions, the catalyst was ramped to $400^{\circ} \mathrm{C}$ at a ramp rate of $20^{\circ} \mathrm{C} \mathrm{min}{ }^{-1}$. This fast ramp rate was used in attempt to observe the catalytic activity of the reduced Pd phase before it oxidized. Data analysis was performed on inhouse developed software (JAQ software), which was used to align, calibrate, normalize, and average spectra. Data from a mass spectrometer were recorded every $\sim 10 \mathrm{~s}$. Using a monochromator frequency of $1 \mathrm{~s}^{-1}$, two spectra were produced per second (one "up," and one "down"). For averaging and analysis, only the "up" spectra were used, or when the monochromator oscillated in the same scan direction. Temperature was linearly interpolated to enable matching each XAS spectra to a well-defined temperature. For linear combination analysis, spectra were deconvoluted between two states: the average of the first 50 spectra and the average of the last 50 spectra. The first 50 spectrum were collected after catalyst reduction reached the steady state, and the last 50 spectra were collected after operando 
measurements reached steady state values. The initial and final state spectra match reference foil and oxide spectra well although particle size effects may exist (Fig. S6).

\section{X-ray photoelectron spectroscopy}

X-ray photoelectron spectra were acquired on a Phi VersaProbe 3 Scanning XPS Microprobe equipped with a hemispherical electron analyzer using $\mathrm{Al}(\mathrm{K \alpha})$ radiation $(1486.4 \mathrm{eV})$. Powder samples were deposited on conductive carbon tape on top of an Al holder, which was outgassed at $10^{-2} \mathrm{~Pa}$ and transferred to an ion-pumped analysis chamber. Throughout data acquisition, pressure in the chamber was maintained below $\sim 5 \times 10^{-7} \mathrm{~Pa}$. For all samples, the incident $\mathrm{x}$-ray spot size was $100 \mu \mathrm{m}$, and an excitation of $100 \mathrm{~W}$ at $20 \mathrm{kV}$ and a pass energy of $280 \mathrm{eV}$ were used. $\mathrm{An}^{+} \mathrm{rr}^{+}$neutralizer and an electron flood gun were used to compensate for $\mathrm{Al}_{2} \mathrm{O}_{3}$ charging, and binding energies (BE) were referenced to the $\mathrm{C} 1 \mathrm{~s}$ peak $(284.8 \mathrm{eV})$ to account for small charging effects.

\section{E. Catalytic characterization}

Prior to catalytic testing, $\sim 200 \mathrm{mg}$ of each catalyst was rapidly thermally annealed to remove organic ligands from synthesis, while preserving the uniform nanocrystal sizes, according to a known procedure. ${ }^{25}$ Each catalyst, post ligand removal, was sieved below $180 \mu \mathrm{m}$ grain size. For light-off curves (Fig. 7), $20 \mathrm{mg}$ catalyst was mixed with $180 \mathrm{mg}$ calcined $\mathrm{Al}_{2} \mathrm{O}_{3}$, which was found to be sufficient to eliminate thermal effects by repeated tests. In these experiments, the same amount of Pd was placed in each bed, with more or less Pt added stoichiometrically. This mixture was loaded into the reactor to give a bed length of about $1.0 \mathrm{~cm}$. This bed rested between two layers of granular quartz which were used for preventing displacement of the catalyst powder and for preheating the reactant gases. The reactor was heated by a square furnace (Micromeritics), and the temperature of the catalyst was measured with a K-type thermocouple inserted inside the reactor, touching the catalytic bed. All experiments were conducted at a total pressure of $1 \mathrm{~atm}$.

Prior to light-off curve measurement, each catalyst was held at $400{ }^{\circ} \mathrm{C}$ for $30 \mathrm{~min}$ in $45 \mathrm{ml} \mathrm{m^{-1 }}$ of 5 vol. $\% \mathrm{O}_{2} / \mathrm{Ar}$ to remove carbonates and residual organics. Next, the samples were cooled to $200{ }^{\circ} \mathrm{C}$, at which reaction gases were introduced $\left(0.5\right.$ vol. $\% \mathrm{CH}_{4}, 4.0$ vol. $\% \mathrm{O}_{2}, 4.2$ vol. $\% \mathrm{H}_{2} \mathrm{O}$, balance $\mathrm{Ar} ; \mathrm{H}_{2} \mathrm{O}$ was introduced by bubbling the reaction mixture through a saturator kept at $30{ }^{\circ} \mathrm{C}$ ). The sample was then ramped in reaction gases to $600^{\circ} \mathrm{C}$ and back to $200{ }^{\circ} \mathrm{C}$ at $10^{\circ} \mathrm{C} \mathrm{min}^{-1}$. Next, the catalyst was flushed with $\mathrm{Ar}$ and then reduced at $400{ }^{\circ} \mathrm{C}$ in $45 \mathrm{ml} \mathrm{min}{ }^{-1}$ of 5 vol. $\% \mathrm{H}_{2} /$ Ar to reduce the catalyst to metallic $\mathrm{Pd}$. The catalyst was subsequently cooled to $200{ }^{\circ} \mathrm{C}$, purged with $45 \mathrm{ml} \mathrm{min}{ }^{-1}$ Ar for $10 \mathrm{~min}$, at which point reaction gases were reintroduced. Again, the catalyst was ramped in reaction gases to $600^{\circ} \mathrm{C}$ and back to $200^{\circ} \mathrm{C}$ at $10^{\circ} \mathrm{C} \mathrm{min}-1$.

For temperature-programmed oxidation, $\mathrm{O}_{2}-\mathrm{TPO}$ and temperature-programmed reduction, $\mathrm{CH}_{4}$-TPR, $200 \mathrm{mg}$ of pure catalyst 1 wt. $\% \mathrm{Pd} / \mathrm{Al}_{2} \mathrm{O}_{3}$ was introduced, undiluted, into the quartz reactor. The catalyst was ramped in $23 \mathrm{ml} \mathrm{min}^{-1} 4$ vol. \% $\mathrm{O}_{2} / \mathrm{Ar}$ to $500{ }^{\circ} \mathrm{C}$ at $10^{\circ} \mathrm{C} \mathrm{min}^{-1}$ and back to $100^{\circ} \mathrm{C}$ in an oxidative cleaning step. Next, $23 \mathrm{ml} \mathrm{min}{ }^{-1}$ of 0.5 vol. $\% \mathrm{CH}_{4} / \mathrm{Ar}$ was introduced, the feed was stabilized, and the catalyst was ramped until $\sim 400{ }^{\circ} \mathrm{C}$ and cooled back down to $100^{\circ} \mathrm{C}$ in $\mathrm{CH}_{4} / \mathrm{Ar}$. Next, 4 vol. \% $\mathrm{O}_{2} / \mathrm{Ar}$ was reintroduced, and the catalyst was ramped to $450{ }^{\circ} \mathrm{C}$ in the $\mathrm{O}_{2}$ mixture. The same experiments were performed in the presence of $\mathrm{H}_{2} \mathrm{O}$. All temperature ramps were performed at $10^{\circ} \mathrm{C} \mathrm{min}^{-1}$.

For transient activation experiments, the catalyst was oxidized

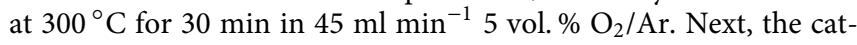
alyst was purged with $\mathrm{Ar}$ and then reduced at $300{ }^{\circ} \mathrm{C}$ for $30 \mathrm{~min}$ in $45 \mathrm{ml} \mathrm{min}^{-1} 5$ vol. $\% \mathrm{H}_{2} / \mathrm{Ar}$. Finally, the catalyst was ramped to $400{ }^{\circ} \mathrm{C}$ at $20^{\circ} \mathrm{C} \mathrm{min}^{-1}$ in $45 \mathrm{ml} \mathrm{min}^{-1}$ pure Ar, at which point reaction gases were introduced. Conversion was monitored vs time to assess catalyst activation or deactivation.

\section{RESULTS AND DISCUSSION}

\section{A. Monometallic Pd nanoparticles}

In this work, we study catalysts with uniform particle sizes of $2.5 \mathrm{~nm}, 7.9 \mathrm{~nm}$, and $14.7 \mathrm{~nm}$ supported on $\gamma-\mathrm{Al}_{2} \mathrm{O}_{3}$ to gain new insights into the redox dynamics of monometallic Pd combustion catalysts [Figs. 1(a)-1(c)]. Different particle sizes should
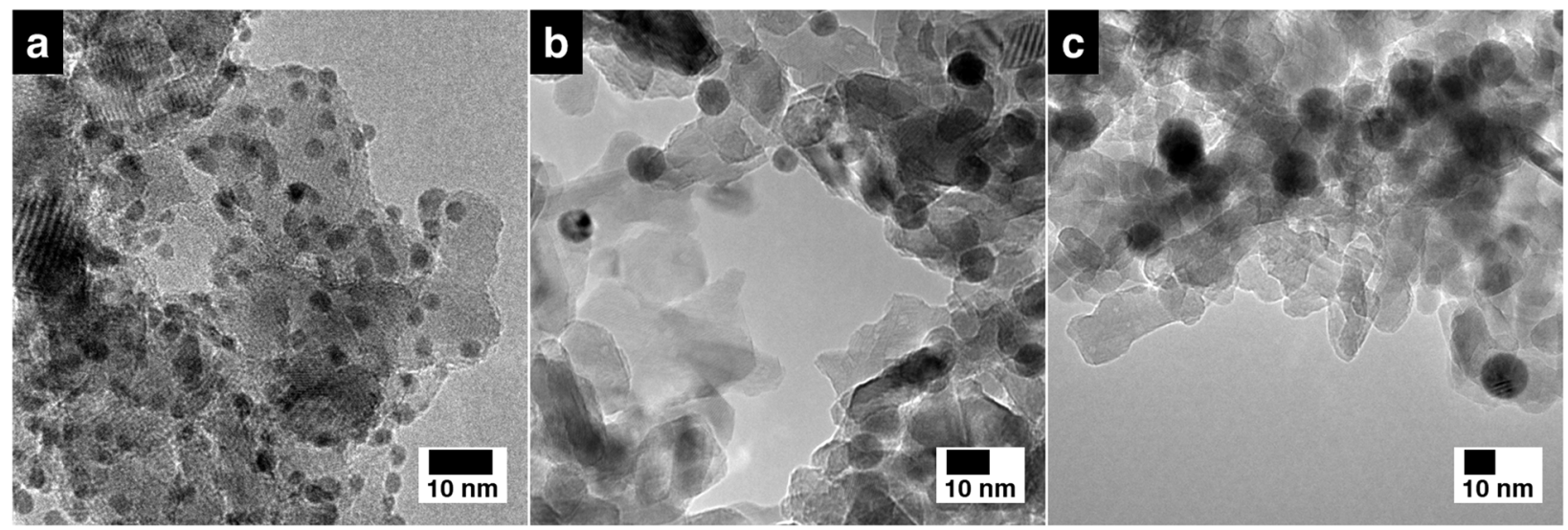

FIG. 1. Transmission electron microscopy of monometallic $\mathrm{Pd} / \mathrm{Al}_{2} \mathrm{O}_{3}$ materials. Representative TEM images of (a) $2.5 \mathrm{~nm} \mathrm{Pd} / \mathrm{Al}_{2} \mathrm{O}_{3}$, (b) $7.9 \mathrm{~nm} \mathrm{Pd} / \mathrm{Al}_{2} \mathrm{O}_{3}$, and (c) $14.7 \mathrm{~nm}$ $\mathrm{Pd} / \mathrm{Al}_{2} \mathrm{O}_{3}$ catalysts. All catalysts are 1.0 wt. \% $\mathrm{Pd} / \mathrm{Al}_{2} \mathrm{O}_{3}$. Particle size distributions have been reported in a past work. 
demonstrate different kinetics and thermodynamics of oxidation and reduction and consequently, different catalytic reactivity. ${ }^{1}$ Therefore, uniform nanoparticle catalysts were chosen in order to ensure that bulk oxidation state measurements could be easily correlated with a very specific structure at the single nanoparticle level. In polydisperse $\mathrm{Pd} / \mathrm{Al}_{2} \mathrm{O}_{3}$ catalysts, the larger aggregates that dominate bulk property measurements are not necessarily representative of the catalytically active phase.

To accurately correlate the oxidation state of these three materials with catalytic combustion activity, operando quick x-ray absorption spectroscopy (QEXAFS) was performed on the three Pd nanocrystal sizes of $\mathrm{Pd} / \mathrm{Al}_{2} \mathrm{O}_{3}$ catalysts (Fig. 2). Past work from our group utilized X-ray Absorption Near Edge Structure (XANES) to characterize the oxidation state of $\mathrm{Pd} / \mathrm{Al}_{2} \mathrm{O}_{3}$ and $\mathrm{Pd} / \mathrm{Ce}_{0.2} \mathrm{Z}_{0.8} \mathrm{O}_{2}$ catalysts under methane combustion conditions. In that work, the fully oxidized state was observed, but no transition or comparison between the Pd and PdO states was performed due to the relatively long acquisition time of $20 \mathrm{~min} /$ spectrum. $^{6}$ In this work, a rapid scanning monochromator was used to capture the dynamics of the oxidation processes, which occurred within a period of 5-10 min. For each particle size, the sample was first ramped up in 5 vol. \% $\mathrm{O}_{2} /$ Ar to $450{ }^{\circ} \mathrm{C}$ and then reduced at room temperature with $\mathrm{H}_{2}$ two times prior to operando collection. Next, samples were reduced at room temperature until only Pd metal was observed (Fig. S6). At this point, dry methane combustion gases were introduced at room temperature, and the catalyst bed was rapidly ramped to $450{ }^{\circ} \mathrm{C}$ at

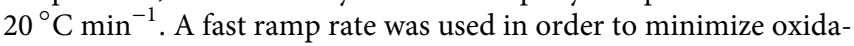
tion and preserve the metallic Pd state so as to observe catalytic of the metallic Pd state prior to oxidation to PdO.

Pd redox behavior of $7.9 \mathrm{~nm}$ and $14.7 \mathrm{~nm}$ NPs shows a similar oxidation process, where Pd is mostly present in the metallic state until $250^{\circ} \mathrm{C}$, after which oxidation occurs in the temperature range $300-450{ }^{\circ} \mathrm{C}$ [Figs. 2 (b) and 2(c)]. However, the $2.5 \mathrm{~nm} \mathrm{Pd}$ particles show a more gradual increase in the average Pd oxidation state until $250^{\circ} \mathrm{C}$, at which point a more dramatic oxidation process begins [Fig. 2(a)]. All catalysts were fully oxidized by the end of the experiment, at $450^{\circ} \mathrm{C}$ (Fig. S3). Most notably, no combustion activity was observed over a fully metallic catalyst. Instead, across all three particle sizes, Pd oxidation occurred prior to catalytic combustion. These data suggest that nanoparticle oxidation, of at least the surface, is necessary for methane combustion and conclude that an oxidized surface is the necessary and active surface for methane combustion.

Using linear combination analysis, we can determine the fraction of PdO observed for each catalyst at methane combustion activity onset. For comparison, the PdO content of each catalyst was measured at $5 \% \mathrm{CH}_{4}$ conversion, where methane conversion was sufficiently above the baseline methane inlet value. At this value, we observe that the $2.5 \mathrm{~nm}$ Pd catalyst was $27 \%$ oxidized, the $7.9 \mathrm{~nm}$ Pd catalyst was $24 \%$ oxidized, and the $14.7 \mathrm{~nm}$ catalyst was $17 \%$ oxidized. If Pd oxidation occurs uniformly across the NP surface, where Pd oxidizes from the surface toward the core, we can approximate the thickness of the PdO layer that would be consistent to the measured PdO content, as reported in Fig. 3. Using the value determined at $5 \% \mathrm{CH}_{4}$ conversion, for the $2.5 \mathrm{~nm} \mathrm{Pd} \mathrm{NPs}, 27 \% \mathrm{PdO}$ would correspond to an oxide shell of $2.0 \AA$, while for the largest nanoparticle sizes $(14.7 \mathrm{~nm})$, the metal oxide content of $17 \%$ corresponds to the PdO thickness of $7.4 \AA$. This model suggests that thin PdO surfaces (1-3 PdO unit cells) are active for the methane combustion reaction, suggesting that formation of a surface oxide is sufficient for methane combustion activity. However, we note that there are other potential explanations; if Pd oxidation initiates at under coordinated sites, then PdO may instead form a larger nanocluster on a specific part of the surface rather than a conformal oxidized shell. In either model of methane oxidation, our data directly shows that at least partially oxidized nanoparticle is necessary in order to detect appreciable activity for methane combustion. This claim is uniquely made using monodisperse nanoparticles, where each nanoparticle within a sample should oxidize at the same rate.
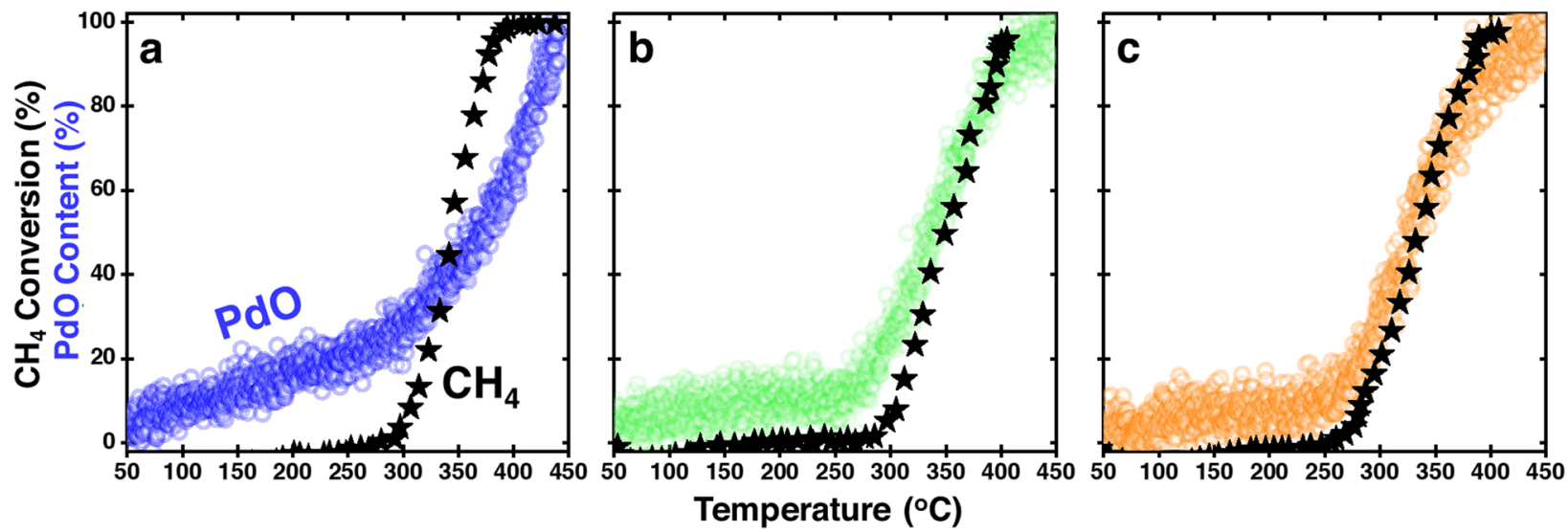

FIG. 2. Operando QEXAFS of $\mathrm{Pd} / \mathrm{Al}_{2} \mathrm{O}_{3}$ materials. Linear combination fitting of operando x-ray absorption near edge spectroscopy of $\mathrm{Pd} / \mathrm{Al}_{2} \mathrm{O}_{3}$ materials during dry lean methane combustion for (a) $2.5 \mathrm{~nm} \mathrm{Pd} / \mathrm{Al}_{2} \mathrm{O}_{3}$, (b) $7.9 \mathrm{~nm} \mathrm{Pd} / \mathrm{Al}_{2} \mathrm{O}_{3}$, and (c) $14.7 \mathrm{~nm} \mathrm{Pd} / \mathrm{Al}_{2} \mathrm{O}_{3}$. Colored open circles plot the results of the relative amount of PdO in each catalyst as a function of temperature during the light-off experiment. Black stars plot the corresponding methane combustion activity, measured simultaneously via online mass spectrometry. 


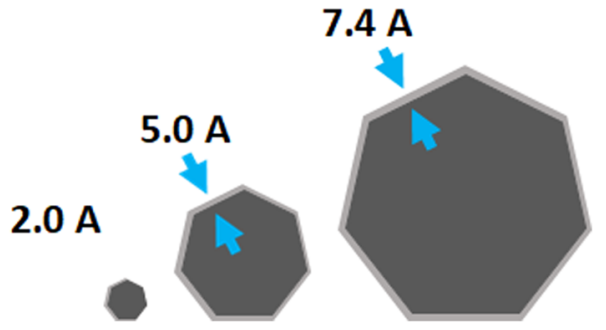

FIG. 3. Schematic of PdO thickness in the concentric oxidation model. Schematic showing oxide shell thickness at $5 \% \mathrm{CH}_{4}$ conversion-for $2.5 \mathrm{~nm} \mathrm{NPs}$, this is at $27 \% \mathrm{PdO}$, for $7.9 \mathrm{~nm} \mathrm{NPs}$, this is at $24 \% \mathrm{PdO}$, and for $14.7 \mathrm{~nm} \mathrm{NPs}$, this is at $17 \%$ PdO.

To further demonstrate that the redox properties of uniform Pd nanocrystal catalysts are related to the methane combustion activity, temperature-programmed oxidation $\left(\mathrm{O}_{2}-\mathrm{TPO}\right)$ with 4 vol. $\% \mathrm{O}_{2} / \mathrm{Ar}$ and temperature-programmed reduction $\left(\mathrm{CH}_{4}\right.$ TPR) with 0.5 vol. $\% \mathrm{CH}_{4} / \mathrm{Ar}$ were performed with and without the presence of steam [Figs. 4(a), 4(b), 4(d), and 4(e)]. Steam is often found in high concentration in emissions control reactions and is a well-known poison for low-temperature combustion activity. $^{3}$

Interestingly, the redox properties of $\mathrm{Pd} / \mathrm{Al}_{2} \mathrm{O}_{3}$ were observed to be a function of the concentration of steam in the gas mixture. The oxidation of Pd is shifted only slightly in the presence of steam [Figs. 4(a) and 4(d)], in which the onset of Pd oxidation moves from $\sim 250^{\circ} \mathrm{C}$ to $\sim 260^{\circ} \mathrm{C}$. No products were detected by the online mass spectrometer during the TPO experiments. On the other hand, the reducibility of PdO by methane is dramatically affected by the presence of steam [compare Figs. 4(b) and 4(e)]. Under dry conditions, $\mathrm{PdO}$ begins being reduced by methane at temperatures as low as $160^{\circ} \mathrm{C}$, while in the presence of steam, the reduction does not occur until $250^{\circ} \mathrm{C}$. Note that higher temperature $\mathrm{CH}_{4}$ consumption in the presence of steam is due to methane steam reforming, and not $\mathrm{PdO}$ reduction, as indicated by the formation of partial oxidation products and $\mathrm{H}_{2} \mathrm{O}$ consumption. Additionally, the amount of $\mathrm{CH}_{4}$ consumed in both experiments was found to be very close, despite the difference in peak height, due to different peak widths (Table S2). At low temperatures, it is well established that methane combustion activity suffers due to poisoning of the PdO surface by water. ${ }^{4,31,32}$ This effect is demonstrated in the delayed onset of methane activation due to poisoning of the PdO surface by water. In both TPR experiments, $\mathrm{CO}_{2}$ is observed as the only product, as water produced is likely directly adsorbed onto the $\mathrm{Al}_{2} \mathrm{O}_{3}$ surface. ${ }^{30}$ Overall, these data are consistent with the hypothesis that the poisoning effect of $\mathrm{H}_{2} \mathrm{O}$ for methane combustion is related to the methane activation step on a $\mathrm{PdO}$ surface rather than $\mathrm{O}_{2}$ activation.

From a simple perspective, one might expect that both $\mathrm{O}_{2}$ activation, demonstrated via $\mathrm{O}_{2}-\mathrm{TPO}$, and $\mathrm{CH}_{4}$ activation, demonstrated by $\mathrm{CH}_{4}-\mathrm{TPR}$, are necessary for methane combustion. In this analysis, we performed temperature-programmed oxidation and reduction experiments to understand the temperatures at which $\mathrm{O}_{2}$ can begin to react with $\mathrm{Pd}$ and at which $\mathrm{CH}_{4}$ can react with $\mathrm{PdO}$. Interestingly, these TPO/TPR temperatures correlate well with onset temperatures of catalytic methane combustion activity seen in ignition curves as a function of catalyst pretreatment [Figs. 4(c) and $4(f)$. Without steam, we observe a dramatic effect of catalyst pretreatment on catalytic activity. Here, we find that the oxidized $\mathrm{PdO} / \mathrm{Al}_{2} \mathrm{O}_{3}$ catalyst shows lower-temperature combustion than the reduced $\mathrm{Pd} / \mathrm{Al}_{2} \mathrm{O}_{3}$ catalyst. Starting with the $\mathrm{PdO}$ phase, we observe

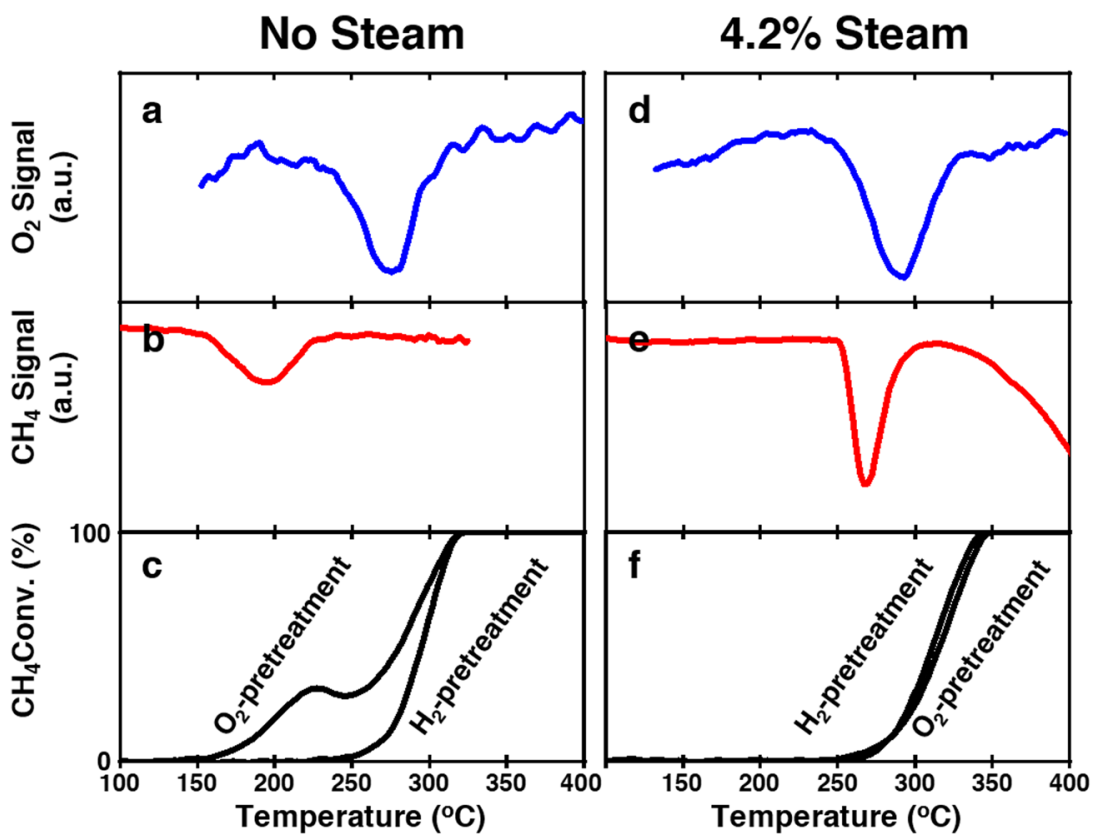

FIG. 4. Temperature-programmed oxidation, reduction, and reaction of 7.9 $\mathrm{nm}$ Pd $(1.0$ wt. $\%) / \mathrm{Al}_{2} \mathrm{O}_{3}$ catalyst with steam (right column) and without (left column). Temperature-programmed oxidation $\left(\mathrm{O}_{2}\right.$ - TPO) (a), reduction $\left(\mathrm{CH}_{4}-\right.$ TPR) (b), and reaction (c) without steam. Temperature-programmed oxidation $\left(\mathrm{O}_{2}\right)(\mathrm{d})$, reduction $\left(\mathrm{CH}_{4}\right)(\mathrm{e})$, and reaction (f) with steam. Note that in (e), increased $\mathrm{CH}_{4}$ consumption at high temperature is due to methane steam reforming and produces syngas products. For reaction experiments (c) and (f), $\mathrm{O}_{2}$ trace indicates an oxidizing pretreatment prior to reactivity and $\mathrm{H}_{2}$ trace indicates a reductive pretreatment prior to reactivity. 
methane combustion begins at the $\mathrm{CH}_{4}$-TPR onset temperature of $160^{\circ} \mathrm{C}$. However, starting with a metallic Pd phase with a reducing pretreatment, we see no combustion onset until $\sim 250^{\circ} \mathrm{C}$, which is the temperature at which $\mathrm{PdO}$ oxidizes as evidenced by TPO [Fig. 4(a)]. These results emphasize that the lowest temperature activity occurs on a PdO phase which readily combusts $\mathrm{CH}_{4}$, while catalytic combustion on Pd does not occur until higher temperatures where the Pd is finally oxidized. In steam, we observe no effect of catalyst pretreatment on catalytic activity, with combustion beginning at $260^{\circ} \mathrm{C}$ in both pretreatment conditions. However, in the presence of steam, $\mathrm{PdO}$ reduction and $\mathrm{Pd}$ oxidation occur at the same temperature of $\sim 260^{\circ} \mathrm{C}$, and, therefore, it is difficult to distinguish whether $\mathrm{Pd}$ oxidation or methane activation is the rate-determining process in the oxidation reduction cycle. Overall, a comparison of pretreatment reactivity and temperature-programmed oxidation and reduction indicates that $\mathrm{PdO}$ existence is a prerequisite to methane combustion.

The above data suggest that even when the catalyst is prereduced to metallic $\mathrm{Pd}$, the pure metallic phase cannot be maintained while methane combustion is occurring. This fact is demonstrated both by operando XAS, as well as comparing TPO/TPR results with catalytic activity. As the prereduced catalyst never shows combustion products at temperatures below $\mathrm{Pd}$ oxidation to $\mathrm{PdO}\left(250^{\circ} \mathrm{C}\right)$, we hypothesize that metallic Pd is not the most active phase for the methane combustion reaction. However, when $\mathrm{Pd}$ is preoxidized to $\mathrm{PdO}$, combustion occurs at temperatures below Pd oxidation $\left(\ll 250^{\circ} \mathrm{C}\right)$, suggesting that $\mathrm{PdO}$ is active at these temperatures. It is worth emphasizing that this low temperature combustion regime $\left(160^{\circ} \mathrm{C}-250{ }^{\circ} \mathrm{C}\right)$ is catalytic because we observe stoichiometric $\mathrm{O}_{2}$ depletion and $\mathrm{CO}_{2}$ formation in this temperature region, demonstrating that we are not simply reducing PdO but performing catalytic combustion on its surface. However, we note that there are still reports on a metallic phase being more active for catalytic combustion. ${ }^{18,20}$ Possible explanations for this include: (1) In situ dehydration of the support or catalyst: it has been shown that in situ heating (in oxidizing or reductive environments) can lead to water removal from the support or active phase surface and artificially inflated activity. This dehydration effect certainly contributes when comparing a calcined-and-stored $\mathrm{PdO}$ material to an in situ reduced and dehydrated Pd material, and this transient activity enhancement due to surface dehydration via in situ calcination was the focus of another work. ${ }^{30}$ (2) Precipitation of nanoclusters from atomic species, in which structural changes might explain enhanced activity due to reducing pretreatments. In other work, we observe that precipitation of particles from nanoclusters and atomic species leads to enhanced activity. ${ }^{24}$

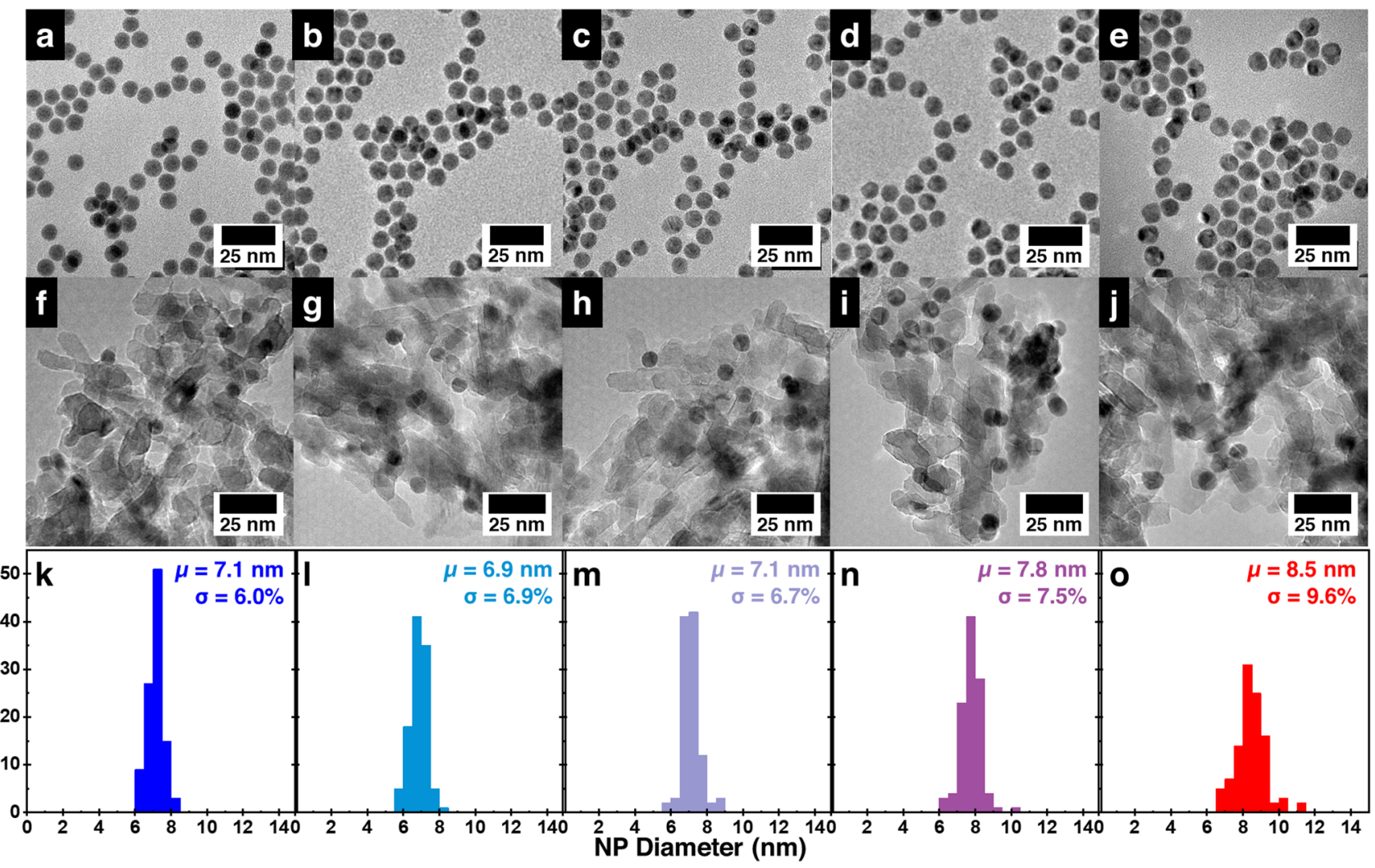

FIG. 5. Characterization of bimetallic $\mathrm{Pt}_{x} \mathrm{Pd}_{1-x} / \mathrm{Al}_{2} \mathrm{O}_{3}$ materials. Colloidally synthesized [(a)-(e)] and $\mathrm{Al}_{2} \mathrm{O}_{3}$-supported [(f)-(j)] $\mathrm{Pt}_{x} \mathrm{Pd}_{1-x} \mathrm{NPs}_{\mathrm{P}}$ with particle size distributions $[(\mathrm{k})-(\mathrm{o})]$. [(a), (f), and (k)] no Pt, [(b), (g), and (l)] 6 at. \% Pt, [(c), (h), and (m)] 10 at. \% Pt, [(d), (i), and (n)] 23 at. \% Pt, and [(e), (j), and (o)] 45 at. \% Pt. All supported catalysts were synthesized to contain 0.1 wt. $\% \mathrm{Pd}$. 


\section{B. Alloyed $\mathrm{Pt}_{\mathrm{x}} \mathrm{Pd}_{1-\mathrm{x}}$ nanoparticles}

It is well-established that monometallic Pt catalysts are significantly less active than monometallic Pd catalysts for fuel-lean methane combustion, ${ }^{16,21,33}$ so the analysis of bimetallic materials will focus on how Pt alters the oxidation state and catalytic activity of Pd. In bimetallic Pt-Pd catalysts, an understanding of relevant oxidation states is further complicated by coexisting NP sizes and alloy structures found at nominal bimetallic compositions. In fact, works have recently demonstrated that methods utilizing incipient wetness impregnation will generate coexisting populations of various alloys, monometallic species, and single atoms. ${ }^{22,23}$ However, in catalysts where Pd may coexist in different oxidation states in different particles, it can be challenging to determine which oxidation state is the most active. Using colloidal methods, we can independently tune particle size and composition, such that all Pd present should be in the same oxidation state within each catalyst.

Size-controlled $\mathrm{Pt}_{\mathrm{x}} \mathrm{Pd}_{1-\mathrm{x}}$ alloyed nanoparticles were synthesized in order to investigate the effect of alloy composition on $\mathrm{Pd}$ oxidation catalysis. Colloidal seed-mediated approaches were used, in which a specific amount of Pt was doped into $7.1 \mathrm{~nm}$ Pd NPs in order to maintain particle size while changing particle composition. In these materials, particle size was maintained between 6.9 and $8.5 \mathrm{~nm}$, while composition was varied between 6 at. \% Pt and 45 at. \% Pt [Figs. 5(a)-5(e)]. Pt content was confirmed by ICP-MS, which matched values obtained from the EDS analysis closely (Table S1). Higher Pt content materials were not studied because Pt-rich combustion materials exhibit decreased activity compared to monometallic Pd and Pt-poor combustion materials. ${ }^{16,21}$ The colloidal nanoparticles were deposited onto a calcined $\gamma-\mathrm{Al}_{2} \mathrm{O}_{3}$ support at $0.1 \mathrm{wt}$. \% for Pd metal loading. These materials represent a series of samples with similar size distribution but varied compositions.

A colloidal approach to making alloyed nanocrystal catalysts has been previously used to synthesize alloy nanoparticles, where each NP was demonstrated to contain both Pt and Pd components. ${ }^{9,16}$ For the supported $\mathrm{Pt}_{\mathrm{x}} \mathrm{Pd}_{1-\mathrm{x}}$ materials, there exist no significant contrast differences with each nanoparticle via HAADF-STEM imaging, which supports the uniformity of the alloyed nanocrystal structure (Fig. 6). Additionally, high-magnification EDS-mapping shows that both signals of Pd and Pt are found in each individual nanoparticle with no measurable signs of elemental segregation or enrichment within any single particle studied, demonstrating the compositional uniformity of the colloidal nanocrystal catalysts as synthesized. More representative elemental maps, single particle statistics, and raw spectra are shown in Figs. S2-S5. Here, we observe $90 \%$ of particles between 55 and 35 at. \% Pt, with a mean Pt content of 41 at. \%, in good agreement with the ICP measured value of 45 at. \% Pt. No monometallic Pt or Pd nanoparticles were observed.

The alloyed samples were tested for methane combustion in the presence of steam. In order to observe the effect of catalyst pretreatment on combustion activity, activity was measured following either oxidizing or reducing pretreatments at $300^{\circ} \mathrm{C}$ using either $5 \% \mathrm{O}_{2} / \mathrm{Ar}$ or $5 \% \mathrm{H}_{2} / \mathrm{Ar}$ (Fig. 7). Typical reports in the literature use either one or the other pretreatment condition. In many reports, as-synthesized catalysts are tested directly after (oxidative)

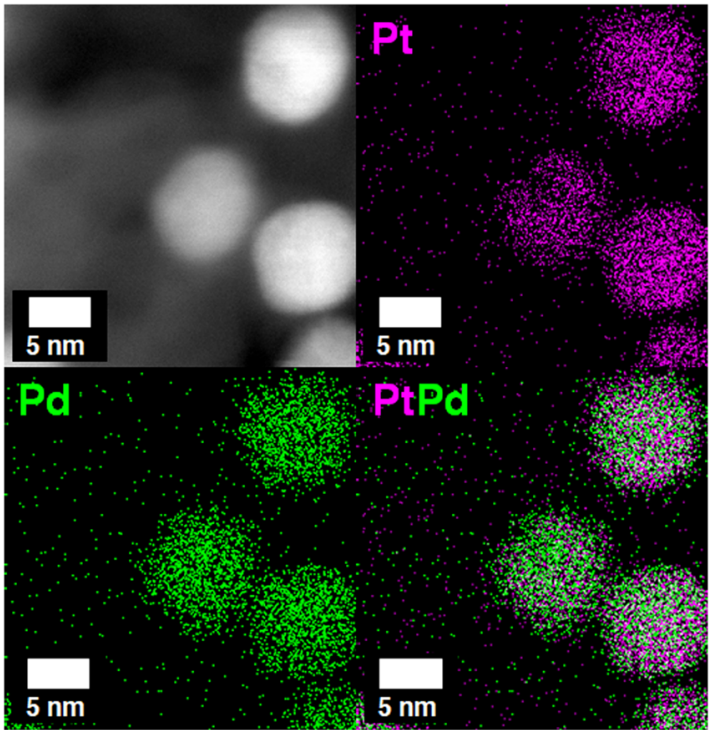

FIG. 6. Uniformly alloyed $\mathrm{Pt}_{0.45} \mathrm{Pd}_{0.55}$ supported on $\mathrm{Al}_{2} \mathrm{O}_{3}$. HAADF-STEM image and elemental mapping via energy dispersive $x$-ray spectroscopy of $\mathrm{Pt}_{0.45} \mathrm{Pd}_{0.55} / \mathrm{Al}_{2} \mathrm{O}_{3}$ collected at a low beam-current of $45 \mathrm{pA}$. Both maps are constructed from the L-edge.

calcination in air or in situ reduction is performed to "activate" the material. Interestingly, we observe that $\mathrm{O}_{2}$ and $\mathrm{H}_{2}$ pretreatments lead to different activity levels as a function of the composition of the $\mathrm{Pt}_{\mathrm{x}} \mathrm{Pd}_{1-\mathrm{x}} \mathrm{NPs}$. As observed in Fig. 4(f), the monometallic $\mathrm{Pd} / \mathrm{Al}_{2} \mathrm{O}_{3}$ catalyst is insensitive to pretreatment in the presence of steam. For the monometallic Pd catalyst and alloyed Pt catalysts up to 10 at. \% $\mathrm{Pt}$, the different pretreatments have minimal effect on catalytic activity [Figs. 7(a)-7(c)]. However, Pd materials with higher Pt content (23 at. \% or 45 at. \%) show notable methane combustion activity differences whether they are preoxidized or prereduced. $\mathrm{O}_{2}$ pretreatments result in the catalyst reaching $50 \% \mathrm{CH}_{4}$ conversion at 30-40 ${ }^{\circ} \mathrm{C}$ low temperature [Figs. $7(\mathrm{~d})-7(\mathrm{e})$ ] compared to using $\mathrm{H}_{2}$ for the pretreatment. Overall, a compositional pretreatment effect is observed with increased Pt content leading to increased sensitivity to catalyst pretreatment as evidenced by the temperature difference to reach $50 \%$ conversion between the two conditions [Fig. 7(f)]. For all materials, an oxidizing pretreatment shows equal or better activity for the methane combustion reaction.

For the monometallic Pd catalyst, pretreatment insensitivity is explained by the TPO/TPR experiments mentioned previously (Fig. 3). In the presence of steam, we find the TPR and TPO temperatures to be very close and, therefore, expect no effect of catalyst pretreatment. However, we observe an effect on $\mathrm{Pt}_{\mathrm{x}} \mathrm{Pd}_{1-\mathrm{x}}$ alloys, where increased Pt content leads to decreased activity after reductive pretreatments. Recent studies have demonstrated that in a 1:2 Pt:Pd catalyst, Pt alloying led to decreased PdO content at higher temperatures due to the more reduced Pd character. ${ }^{21}$ Therefore, it is likely that in 23 at. \% and 45 at. \% catalysts, Pt keeps Pd in a more reduced state, leading to decreased catalytic activity. However, pretreatment in oxygen allows a more significant fraction of Pd to be oxidized and, thus, results in higher light-off activities. Therefore, 

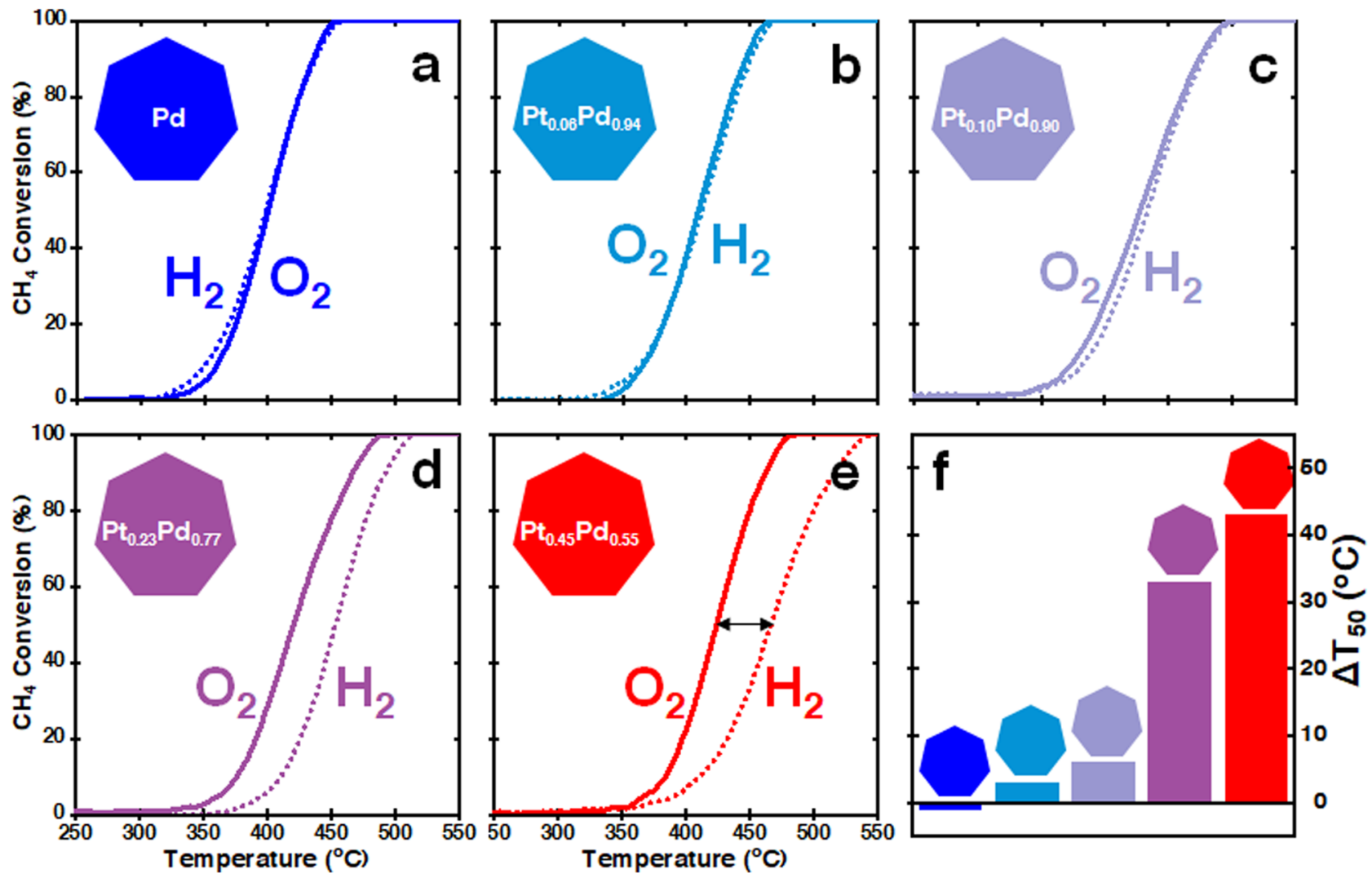

FIG. 7. Methane combustion activity vs catalyst pretreatment. [(a)-(e)] Catalyst activity testing vs pretreatment condition. Each catalyst was in situ pretreated at $300{ }^{\circ} \mathrm{C}$ for $30 \mathrm{~min}$ in $5 \% \mathrm{O}_{2} / \mathrm{Ar}$ and tested for methane combustion with steam. Next, each catalyst was reduced at $300^{\circ} \mathrm{C}$ for $30 \mathrm{~min}$ in $5 \% \mathrm{H}_{2} / \mathrm{Ar}$ and retested for methane combustion with steam. (f) Summary of differences in temperature of $50 \%$ conversion between $\mathrm{O}_{2}$ pretreatment and $\mathrm{H}_{2}$ pretreatment. A positive $\Delta \mathrm{T}_{50}$ indicates higher activity with an oxidative pretreatment.

even for Pt alloys, decreased activity can be related to slower oxidation of Pd to PdO. To explore this hypothesis, further experiments were performed to investigate the relationship between the oxidation state and activity in these well-defined bimetallic materials.

To better understand the oxidation and activation process of $\mathrm{Pt}_{\mathrm{x}} \mathrm{Pd}_{1-\mathrm{x}}$ alloys, the catalysts were reduced in situ to the metallic state at $300^{\circ} \mathrm{C}$, at which point they were exposed to reaction gases at $400{ }^{\circ} \mathrm{C}$ (Fig. 8). At $400^{\circ} \mathrm{C}$, nanoparticle sintering is unlikely to occur, as demonstrated in a previous work, where similar catalysts were stable to at least $460^{\circ} \mathrm{C} .{ }^{24}$ At $400^{\circ} \mathrm{C}$, the effect of $\mathrm{H}_{2} \mathrm{O}$ on $\mathrm{Pd}$ activity is minimal, and instead we expect changes in activity to be mainly due to oxidation of Pd to PdO. Thus, transient activation processes are used to understand the kinetics of this oxidation process. At these temperatures and conditions, we know from TPO experiments that a monometallic Pd catalyst would oxidize. Indeed, when combustion gases are introduced, each catalyst activates significantly with time on stream; while the Pd-rich catalyst triples its activity within the first hour on-stream and quickly stabilizes, the Ptrich catalyst, which shows a lower initial activity, very slowly triples its activity over a period of $5 \mathrm{~h}$. A steady state is not quickly reached. Also, additional in situ reduction after the first $5 \mathrm{~h}$ activation period

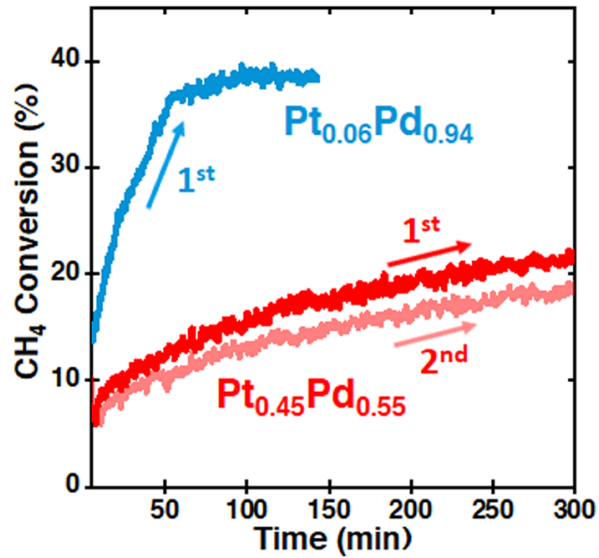

FIG. 8. Transient activation of prereduced $\mathrm{Pt}_{x} \mathrm{Pd}_{1-x}$ alloys. Transient activation for methane combustion of $\mathrm{Pt}_{0.06} \mathrm{Pd}_{0.94} / \mathrm{Al}_{2} \mathrm{O}_{3}$ and $\mathrm{Pt}_{0.45} \mathrm{Pd}_{0.5} / \mathrm{Al}_{2} \mathrm{O}_{3}$ isothermal at $400^{\circ} \mathrm{C}$. Catalysts were reduced in situ at $300^{\circ} \mathrm{C}$ in $5 \% \mathrm{H}_{2} / \mathrm{Ar}$ for $30 \mathrm{~min}$, flushed with pure $\mathrm{Ar}$ for $10 \mathrm{~min}$, and then reaction gases were introduced at $400^{\circ} \mathrm{C}$. $1 \mathrm{st}$ indicates behavior after initial reduction; 2 nd indicates a second reduction after the first transient process. 
decreases activity back to the original level, with the sample then again reactivating on stream.

For both $\mathrm{Pt}_{\mathrm{x}} \mathrm{Pd}_{1-\mathrm{x}}$ compositions, the catalytic activity increases with time on stream. This is likely related to oxidation of the originally reduced materials at $400^{\circ} \mathrm{C}$. The $\mathrm{Pt}_{0.06} \mathrm{Pd}_{0.94} / \mathrm{Al}_{2} \mathrm{O}_{3}$ catalyst quickly activates and activity stabilizes likely because the relatively small Pt content does not slow the kinetics of Pd oxidation significantly. However, at an increased Pt content of 45 at. \%, we notice very slow activation of the alloy material. These results agree with the previous findings that an alloyed Pt-Pd catalyst shows slower Pd oxidation compared to a monometallic Pd catalyst. ${ }^{21}$ Furthermore, the Pt-rich material was rereduced after the first transient experiment, at which point we see a similar activation process occurring with time on stream. This strongly suggests that this activation is related to the reversible change in the Pd oxidation state as processes such as sintering would not show such a reversible behavior. This reversibility is consistent with previous work where sintered Pt-Pd alloys show inflection points in their activity at high temperatures, likely due to a reduction in a segregated PdO phase. The demonstrated transient activation behavior from the metallic state can be used to interpret Fig. 7. Here, we see that prereduced Pt-rich alloys show lower activation than preoxidized samples due to the slow oxidation kinetics of Pt-rich alloys. From pretreatment experiments and on-stream activation experiments, we learn that (1) all catalysts show equal or better activity following $\mathrm{O}_{2}$ pretreatments compared to $\mathrm{H}_{2}$ treatments and (2) reducing pretreatments more severely deactivate Pt-rich alloys than $\mathrm{Pt}_{\mathrm{x}} \mathrm{Pd}_{1-\mathrm{x}}$ alloys with a lower Pt content.

Ex-situ X-ray photoelectron spectroscopy (XPS) and EDSmapping were used to characterize the oxidized alloys at different stages of oxidation (Fig. 9). To study the rate and extent of Pd oxidation in the alloyed materials, XPS measurements were taken after the catalyst was heated in static air at $450{ }^{\circ} \mathrm{C}$ for $5 \mathrm{~min}, 30 \mathrm{~min}, 120 \mathrm{~min}$, and $300 \mathrm{~min}$ in a calcination furnace. In these experiments, both catalysts start with $\mathrm{Pd}$ in the fully metallic state. When treated at $450{ }^{\circ} \mathrm{C}$, both catalysts show increased oxide content, evidenced by the increase in $\mathrm{Pd}_{5 / 2}$ binding energy, shifting toward that of bulk $\mathrm{PdO}$ at $336.5 \mathrm{eV}$ [Fig. 9(a)]. While both catalysts remain metallic after calcination for $5 \mathrm{~min}$, the dilute Pt alloy quickly oxidizes to bulk
$\mathrm{PdO}$ within $30 \mathrm{~min}$, at which point no further oxidation is observed. However, the Pt-rich alloy shows continuous oxidation even past 120 min, with a broad Pd peak due to the contributions of oxidized and metallic Pd. Finally, after $300 \mathrm{~min}$, the $\mathrm{Pt}_{0.45} \mathrm{Pd}_{0.55} / \mathrm{Al}_{2} \mathrm{O}_{3}$ sample shows a bulk $\mathrm{PdO}$ state, similar to the $\mathrm{Pt}_{0.06} \mathrm{Pd}_{0.94} / \mathrm{Al}_{2} \mathrm{O}_{3}$ sample. The oxidation kinetics observed via XPS agree well with the transient activation behavior observed in Fig. 8. While the Pt-poor alloy was largely oxidized within the first $30 \mathrm{~min}$, the Pt-rich alloy took up to $300 \mathrm{~min}$ : this result correlates well with the rapid activation of the Pt-poor catalyst for methane combustion and the slow activation of the Pt-rich material. By correlating the XPS data with the activation experiments, we demonstrate that activity increases as Pd oxidizes and that the rate of this oxidation is a function of Pt concentration in the material. Low Pt content leads to quick oxidation and rapid activation on stream, while high Pt content leads to slow oxidation and slow activation on stream.

Throughout the oxidation, the Pt-rich sample shows no change in the relative intensity between the Pt and Pd peaks via XPS. This indicates that there is no significant enrichment of $\mathrm{PdO}$ on the surface of the material in the form of a core-shell structure as has been suggested in previous studies. ${ }^{23,34}$ Therefore, to get a better understanding of the single-particle nanostructure of the oxidized material, the $\mathrm{Pt}_{0.45} \mathrm{Pd}_{0.55} / \mathrm{Al}_{2} \mathrm{O}_{3}$ catalyst heated for 300 min was studied via EDS-mapping to compare the oxidized catalyst state to the originally uniformly alloyed reduced catalyst state [Fig. 9(b)]. Interestingly, the originally uniformly alloyed NPs evolved into new nanostructures. High-Angle Annular Dark Field Scanning Transmission Electron Microscopy (HAADF-STEM) imaging, which is sensitive to mass contrast, demonstrates that each particle is no longer uniform in composition. The EDS-mapping shows that in many nanoparticles, a near phase-pure Pd phase segregates out, leaving an alloyed Pt-Pd phase behind, in a segregated nanoparticle structure. The majority of the $\mathrm{Pd}$ phase is likely $\mathrm{PdO}$ due to the weak contrast in HAADF-STEM imaging and the highly oxidized Pd identified in the XPS spectra. Therefore, contrasting to previous claims of a core-shell PdO@PtPd structure, ${ }^{23,34}$ we propose a $\mathrm{PdO} / \mathrm{PtPd}$ structure as the operating phase, where $\mathrm{PdO}$ has segregated out as a separate phase, but not existing as a conformal core-shell structure. This agrees with the XPS

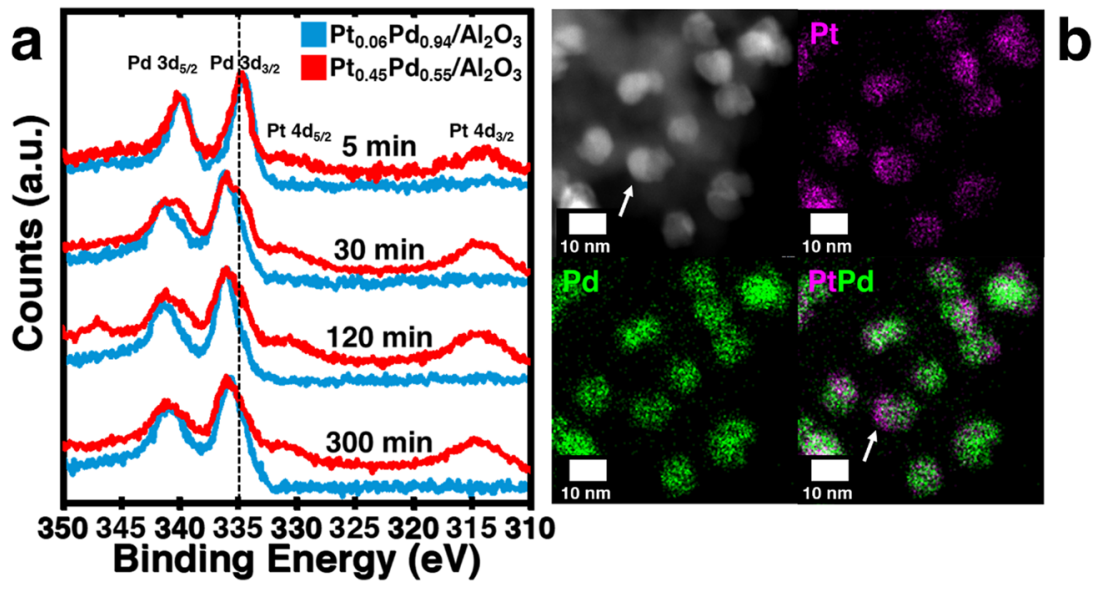

FIG. 9. Oxidation and phasesegregation. (a) $\mathrm{Pd}(3 \mathrm{~d})$ and $\mathrm{Pt}(4 \mathrm{~d})$ XPS spectra of alloyed samples with different calcination treatments at $450^{\circ} \mathrm{C}$ in static air. The dotted vertical line indicates $335 \mathrm{eV}$ of metallic $\mathrm{Pd}$. EDS mapping of $\mathrm{Pt}_{0.45} \mathrm{Pd}_{0.55} / \mathrm{Al}_{2} \mathrm{O}_{3}$ catalysts after $450^{\circ} \mathrm{C} 5 \mathrm{~h}$ in air. (b) Elemental mapping demonstrates segregation of a Pt-rich phase from a low contrast Pd-rich phase. Maps are from the Pt L-edge and the Pd L-edge. 
spectra, which show no surface enrichment of $\mathrm{PdO}$ in the material. $\mathrm{Pt} / \mathrm{Pd}$ catalysts aged at $750{ }^{\circ} \mathrm{C}$ have previously been analyzed via EDS-mapping, but the observed structure was uniformly alloyed Pt-Pd aggregates coexisting with small $\mathrm{PdO}$ nanoparticles. ${ }^{22}$ No core-shell or segregated structures were observed. Here, we demonstrate that for certain particle compositions and sizes, elemental segregation is indeed possible at the single particle level. In fact, this segregation yields a catalytically active phase compared to the relatively inactive, yet homogeneously alloyed initial nanoparticle state.

\section{CONCLUSIONS}

In this contribution, we study the formation of PdO in sizeand composition-controlled $\mathrm{Pd} / \mathrm{Pt}$ bimetallic nanoparticle catalysts. By utilizing highly controlled active phases, we ensure that the measured oxidation states are related to the specific nanoparticle structures synthesized. Across particle sizes from 2.5 to $14.7 \mathrm{~nm}$ and across $\mathrm{Pt}_{\mathrm{x}} \mathrm{Pd}_{1-\mathrm{x}}$ alloys, we observe Pd oxidation to be correlated with promoted catalytic activity for methane combustion. On monometallic $\mathrm{Pd} / \mathrm{Al}_{2} \mathrm{O}_{3}$ catalysts, temperature-programmed oxidation and reduction experiments demonstrate methane combustion onsets at Pd oxidation conditions or even earlier if Pd is preoxidized. Across nanoparticle sizes, operando QEXAFS confirms that Pd must oxidize prior to low-temperature methane combustion activity. In homogeneously alloyed $\mathrm{Pt}_{\mathrm{x}} \mathrm{Pd}_{1-\mathrm{x}}$ nanoparticles, enhanced activity is correlated with the oxidative segregation of a PdO phase, as demonstrated by EDS-maps and XPS. We highlight that enhanced activity of $\mathrm{Pt}_{\mathrm{x}} \mathrm{Pd}_{1-\mathrm{x}}$ alloys may not be due to the formation of alloyed nanoparticle surfaces but rather segregation out of an oxidized Pd phase. Overall, we find metallic alloy nanoparticles evolve under oxidizing conditions, with increases in catalytic activity correlated with oxidation of the material.

\section{SUPPLEMENTARY MATERIAL}

Additional characterization data, catalytic activity, and EDS maps of the alloyed samples can be found in supplementary material.

\section{ACKNOWLEDGMENTS}

We gratefully acknowledge support from the U.S. Department of Energy, Chemical Sciences, Geosciences, and Biosciences (CSGB) Division of the Office of Basic Energy Sciences, via Grant No. DE-AC02-76SF00515 to the SUNCAT Center for Interface Science and Catalysis. Part of this work was performed at the Stanford Nano Shared Facilities (SNSF), supported by the National Science Foundation under Award No. ECCS-1542152. Work at the Molecular Foundry was supported by the Office of Science, Office of Basic Energy Sciences, of the U.S. Department of Energy under Contract No. DE-AC02-05CH11231. E.D.G. acknowledges support from the National Science Foundation Graduate Research Fellowship under Grant No. DGE-1656518. A.A. acknowledges support from a Stanford Graduate Fellowship. M.C. acknowledges support from the School of Engineering at Stanford University and from a Terman Faculty Fellowship. We acknowledge the Swiss
Light Source for the provision of beamtime at the SuperXAS beamline.

\section{REFERENCES}

${ }^{1}$ F. Liang, M. Ryvak, S. Sayeed, and N. Zhao, Chem. Cent. J. 6, S4 (2012).

${ }^{2}$ R. B. Jackson, E. I. Solomon, J. G. Canadell, M. Cargnello, and C. B. Field, Nat. Sustain. 2, 436 (2019).

${ }^{3}$ R. A. Dalla Betta, Catal. Today 35, 129 (1997).

${ }^{4}$ M. Monai, T. Montini, R. J. Gorte, and P. Fornasiero, Eur. J. Inorg. Chem. 2018, 2884.

${ }^{5}$ R. J. Farrauto, Science 337, 659 (2012).

${ }^{6}$ J. J. Willis, A. Gallo, D. Sokaras, H. Aljama, S. H. Nowak, E. D. Goodman, L. Wu, C. J. Tassone, T. F. Jaramillo, F. Abild-Pedersen, and M. Cargnello, ACS Catal. 7, 7810 (2017).

${ }^{7}$ H. Yoshida, T. Nakajima, Y. Yazawa, and T. Hattori, Appl. Catal., B 71, 70 (2007).

${ }^{8}$ W. R. Schwartz and L. D. Pfefferle, J. Phys. Chem. C 116, 8571 (2012).

${ }^{9}$ J. J. Willis, E. D. Goodman, L. Wu, A. R. Riscoe, P. Martins, C. J. Tassone, and M. Cargnello, J. Am. Chem. Soc. 139, 11989 (2017).

${ }^{10}$ M. Cargnello, J. J. D. Jaen, J. C. H. Garrido, K. Bakhmutsky, T. Montini, J. J. C. Gamez, R. J. Gorte, and P. Fornasiero, Science 337, 713 (2012).

${ }^{11}$ K. Murata, Y. Mahara, J. Ohyama, Y. Yamamoto, S. Arai, and A. Satsuma, Angew. Chemie Int. Ed. 56, 15993 (2017).

${ }^{12}$ G. Zhu, J. Han, D. Y. Zemlyanov, and F. H. Ribeiro, J. Am. Chem. Soc. 126, 9896 (2004).

${ }^{13}$ Y. H. C. Chin, M. García-Diéguez, and E. Iglesia, J. Phys. Chem. C 120, 1446 (2016).

${ }^{14}$ S. Bong, M. Hazlett, V. Balakotaiah, C. Kalamaras, and W. Epling, Appl. Catal. B: Environ. 223, 67 (2018).

${ }^{15}$ K. Daneshvar, R. Krishna, D. Luss, V. Balakotaiah, S. Bong, C. M. Kalamaras, and W. S. Epling, Chem. Eng. J. 323, 347 (2017).

${ }^{16}$ E. D. Goodman, S. Dai, A. Yang, C. Wrasman, A. Gallo, S. R. Bare, A. S. Hoffman, T. F. Jaramillo, G. W. Graham, X. Pan, and M. Cargnello, ACS Catal. 7, 4372 (2017).

${ }^{17}$ Y. C. Chin, C. Buda, M. Neurock, and E. Iglesia, J. Am. Chem. Soc. 135, 15425 (2013).

${ }^{18}$ A. Hellman, A. Resta, N. M. Martin, J. Gustafson, A. Trinchero, P.-A. Carlsson, O. Balmes, R. Felici, R. Van Rijn, J. W. M. Frenken, J. N. Andersen, E. Lundgren, and H. Gro, J. Phys. Chem. Lett. 3, 678 (2012).

${ }^{19}$ H. Xiong, K. Lester, T. Ressler, R. Schlögl, L. F. Allard, and A. K. Datye, Catal. Lett. 147, 1095 (2017).

${ }^{20}$ H. Xiong, E. Peterson, G. Qi, and A. K. Datye, Catal. Today 272, 80 (2015).

${ }^{21}$ H. Nassiri, K. Lee, Y. Hu, R. E. Hayes, R. W. J. Scott, and N. Semagina, ChemPhysChem 17, 238 (2017).

${ }^{22}$ T. R. Johns, J. R. Gaudet, E. J. Peterson, J. T. Miller, E. A. Stach, C. H. Kim, M. P. Balogh, and A. K. Datye, ChemCatChem 5, 2636 (2013).

${ }^{23}$ H. Nie, J. Y. Howe, P. T. Lachkov, and Y. C. Chin, ACS Catal. 9, 5445 (2019).

${ }^{24}$ E. D. Goodman, A. C. Johnston-Peck, E. M. Dietze, C. J. Wrasman, A. S. Hoffman, F. Abild-Pedersen, S. R. Bare, P. N. Plessow, and M. Cargnello, Nat. Catal. 2, 748 (2019).

${ }^{25}$ M. Cargnello, C. Chen, B. T. Diroll, V. V. T. Doan-nguyen, R. J. Gorte, and C. B. Murray, J. Am. Chem. Soc. 137, 6906 (2015).

${ }^{26}$ C. A. Schneider, W. S. Rasband, and K. W. Eliceiri, Nat. Methods 9, 671 (2012).

${ }^{27} \mathrm{G}$. W. Cliff and G. Lorimer, J. Microsc. 103, 203 (1975).

${ }^{28}$ O. Müller, M. Nachtegaal, J. Just, D. Lützenkirchen-Hecht, and R. Frahm, J. Synchrotron Radiat. 23, 260 (2016).

${ }^{29}$ O. Müller, D. Lützenkirchen-Hecht, and R. Frahm, Rev. Sci. Instrum. 86, 093905 (2015). 
${ }^{30}$ W. Huang, E. D. Goodman, P. Losch, and M. Cargnello, Ind. Eng. Chem. Res. 57, 10261 (2018).

${ }^{31}$ M. Monai, T. Montini, C. Chen, E. Fonda, R. J. Gorte, and P. Fornasiero, ChemCatChem 7, 2038 (2015).

${ }^{32}$ F. Zhang, C. Hakanoglu, J. A. H. Jr., and J. F. Weaver, Surf. Sci. 617, 249 (2013).
${ }^{33}$ R. Burch and P. K. Loader, Appl. Catal., B 5, 149 (1994).

${ }^{34}$ N. M. Martin, J. Nilsson, M. Skoglundh, E. C. Adams, X. Wang, P. Velin, G. Smedler, A. Raj, D. Thompsett, H. H. Brongersma, T. Grehl, G. Agostini, O. Mathon, S. Carlson, K. Nore, F. J. Martinez-casado, Z. Matej, O. Balmes, and P. Carlsson, J. Phys. Chem. C 120, 28009 (2016). 